\title{
An experimental investigation of cold storage in an encapsulated thermal storage tank
}

\author{
Sih-Li Chen ${ }^{\mathrm{a}, *}$, Chin-Lung Chen ${ }^{\mathrm{a}}$, Chun-Chuh Tin ${ }^{\mathrm{a}}$, Tzong-Shing Lee ${ }^{\mathrm{b}}$, \\ Ming-Chun $\mathrm{Ke}^{\mathrm{b}}$ \\ ${ }^{a}$ Department of Mechanical Engineering, National Taiwan University, Taipei 10764, Taiwan, ROC \\ ${ }^{\mathrm{b}}$ Department of Air Conditioning and refrigeration, National Taipei University of Technology, Taipei 10764, Taiwan, ROC
}

Received 1 September 1999; accepted 15 August 2000

\begin{abstract}
This paper experimentally investigates the thermal performance and the pressure drop of an encapsulated thermal storage tank during the charging process. A polyvinyl chloride (PVC) hollow cylinder is used as the thermal storage tank. The cylindrical capsules inside the thermal storage tank utilize water added with nucleation agents as the phase change material (PCM), and the coolant is the aqueous solution of ethylene glycol. A series of experiments were carried out to investigate the effects of the inlet coolant temperature and coolant flow rate on nucleation of capsules, heat transfer and pressure drop of the tank. The results indicate that cool energy can be fully stored in the form of latent heat when the inlet coolant temperature is set below the temperature with $100 \%$ nucleation probability. The lower the inlet coolant temperature and the larger the coolant flow rate, the more efficient the storage tank. A correlation for the pressure drop of coolant during a charging process is also developed. (C) 2000 Elsevier Science Inc. All rights reserved.
\end{abstract}

Keywords: Thermal storage tank; Capsule; Nucleation

\section{Introduction}

The basic concept of the encapsulated thermal storage air-conditioning system utilizes the characteristics of phase change material (PCM) inside capsules in the storage tank, which releases or absorbs a great amount of latent heat during phase change process. This system makes use of off-peak electricity for cool energy that is stored in capsules in the form of latent heat, and releases cool energy by melting capsules for air-conditioning during daytime to achieve the goal of shifting peak power consumption. Water is widely used as the PCM for thermal storage because of such advantages as high latent heat of melting, stability, low cost and easy acquisition, no environmental pollution concern and compatibility with the material of air-conditioning equipment. However, there are a few disadvantages with the use of water as PCM. One of the most serious problems is the subcooling phenomenon that occurs in

\footnotetext{
${ }^{*}$ Corresponding author. Tel.: +886-2-2363-1808; fax: +886-2-23631755.
}

the process of solidifying water during charging of the cold storage.

A number of researchers have studied the thermal characteristics of the storage tank in the ice storage airconditioning system. Saitoh and Hirose [1] studied the thermal characteristics of an encapsulated thermal storage tank experimentally and theoretically. They used disodium phosphate dodecahydrate $\left(\mathrm{Na}_{2} \mathrm{HPO}_{4} / 12 \mathrm{H}_{2} \mathrm{O}\right)$ as PCM to fill cylindrical capsules with an inside diameter of $70.7 \mathrm{~mm}$. They concluded that the main factors affecting the charging process were the capsule size, coolant flow rate, coolant temperature, and capsule material. Kondepudi et al. [2] discussed the effect of Biot number, Stefan number and Fourier number on the thermal performance of cold storage. Laybourn [3] utilized a concept of thermal resistance, which comprised the convective resistance, wall resistance, and ice layer resistance to calculate the cold storage of the tank with rectangular capsules. Arnold [4] analyzed the heat transfer during the freezing and melting process by performing a series of charging and discharging experiments. Chen [5-7] developed a general lump model to predict the thermal performance of a cold storage 


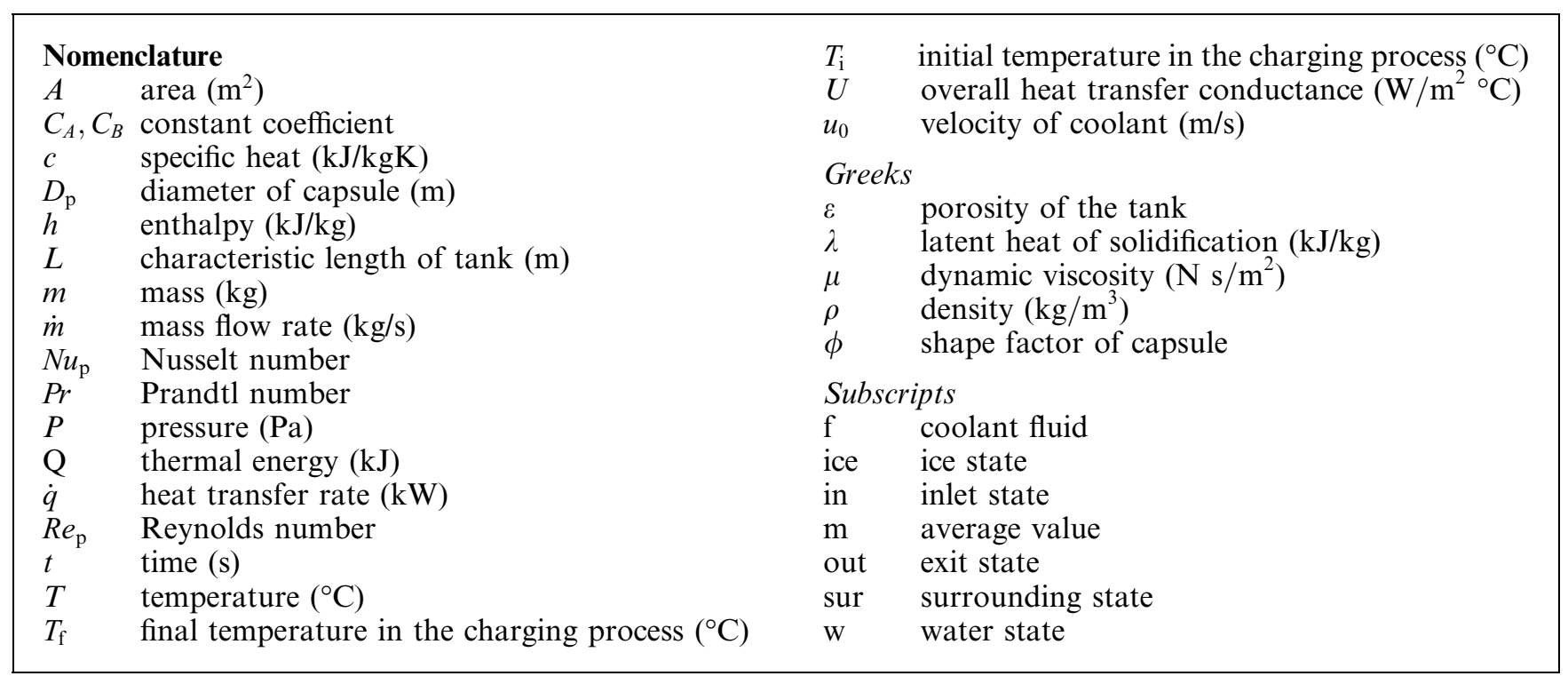

system. The results showed that the lump model is a convenient and simple method to determine the thermal performance of cold storage system. Ryu et al. [8] used a rectangular storage tank with copper tube container and conducted a series of experiments using both vertical and horizontal tank to investigate the heat transfer characteristics. In the area of subcooling of water, Chen [9] conducted a series of experiments to investigate the subcooling phenomenon and the freezing probability of water with and without nucleation agents inside a cylinder. They also verified that the addition of nucleation agents is one of the approaches to effectively improve the subcooling phenomenon.

The major factors affecting the performance of thermal storage tank include the size of capsules, the coolant flow rate, the coolant temperature, the material of the capsules, and the addition of nucleation agents. However, the discussion of the variation of pressure drop in an encapsulated storage tank during charging is still rare in open literatures. The objective of this work is to investigate experimentally the thermal characteristics of an encapsulated thermal storage system using water added with nucleation agents as the PCM by varying the inlet coolant temperature and coolant flow rate. A further understanding on the nucleation behavior of water inside the capsules is established through a series of experiments. The effect of inlet coolant temperature and coolant flow rate on the thermal performance of cold storage is also discussed.

\section{Experimental investigation}

A schematic diagram of the experimental apparatus is shown in Fig. 1. The experimental apparatus consists of two parts: the experimental unit and the measuring unit. The experimental unit, as shown in Fig. 1(a), contains a horizontal thermal storage tank, a large iso- thermal bath and piping system. The encapsulated thermal storage tank is a polyvinyl chloride (PVC) cylinder with an inside diameter of $25 \mathrm{~cm}, 2 \mathrm{~m}$ in length, and $1 \mathrm{~cm}$ thick. To reduce heat gain, the tank is covered with an insulation material of $4 \mathrm{~cm}$ thickness. A total of 42 capsules are horizontally installed in the tank so that the porosity of the tank is 0.378 . The capsules made of PET have a length of $24 \mathrm{~cm}$ and a diameter of $7.3 \mathrm{~cm}$. The PCM inside each capsule is $1000 \mathrm{~g}$ of water with $50 \mathrm{~g}$ nucleation agents. Adding nucleation agents into capsules not only increases the freezing probability of water but also the capsule weight. This prevents the capsules from moving because of the reduced density of the water inside capsules during charging. A small amount of air is put into each capsule to prevent capsules from cracking due to thermal expansion in the phase change process. The aqueous solution of $25 \mathrm{wt} \%$ ethylene glycol is used as coolant. To prevent bypass, the coolant first passes a distributor located in the inlet of the tank to uniformly flow through the capsules.

The measuring unit is shown in Fig. 1(b). There are 29 T-type thermocouples to measure the temperature. Two of them are used to measure the inlet and outlet temperatures of the tank. Eight thermocouples are used to measure the coolant temperature along the axial direction of tank and another 18 thermocouples are inserted into the capsule to measure the center temperature of the capsule. The last one is used to measure the surrounding temperature. An ultrasonic flow meter determines the flow rate of coolant. The measurement of the pressure is carried out by a couple of pressure transducer set in the inlet and outlet of the tank. A hybrid recorder (YOKOGAWA HR-2300) and a personal computer are used for data recording and storage.

A series of charging experiments are performed under conditions of different coolant flow rates and inlet temperatures. There are three different coolant flow rates and inlet coolant temperatures: 5, 10, 20 1/min, and 

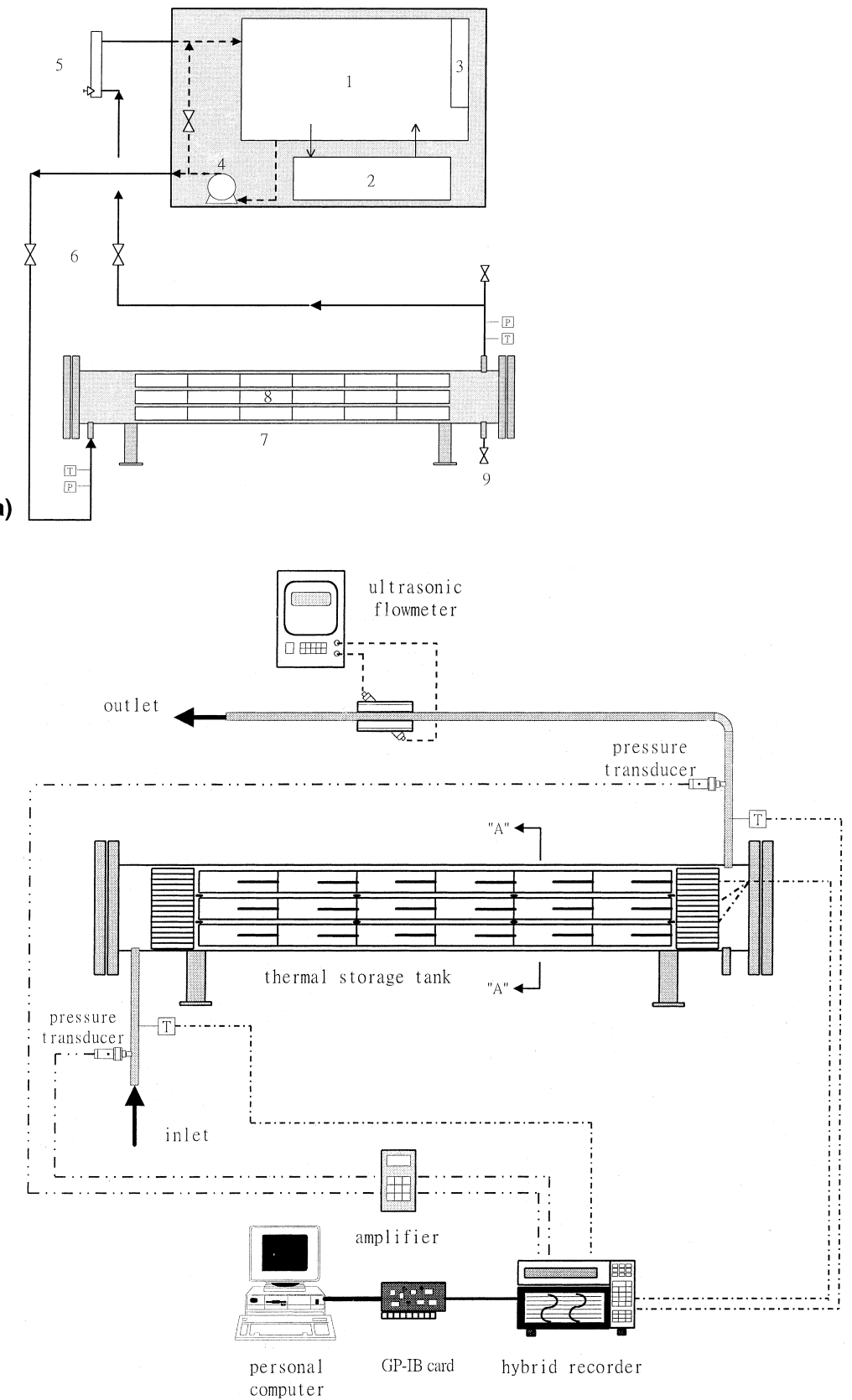

(b)

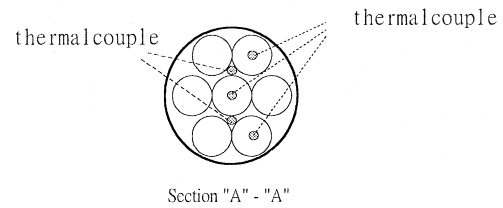

Fig. 1. (a) Schematic diagram of experimental appartus: 1 - coolant bath; 2 - refrigerator; 3 - heater; 4 - pump; 5 - flow meter; 6 - valve; 7 - thermal storage tank; 8 - capsules; 9 - drain. (b) Details of measurement unit.

$-1^{\circ} \mathrm{C},-3^{\circ} \mathrm{C}$, and $-5^{\circ} \mathrm{C}$. Prior to starting each charging test, the experimental unit is cooled down to $10^{\circ} \mathrm{C}$. After reaching initial condition, the experiment starts and the coolant begins to circulate through the tank at the prescribed flow rate and temperature. Each experiment lasts $9 \mathrm{~h}$. All experimental conditions and the thermophysical 
properties of the water, ice and coolant are listed in Tables 1 and 2. Uncertainties of the primary measurements, following the uncertainty analysis proposed by Moffat [10], are tabulated in Table 3.

In order to get the overall average heat transfer coefficient $(U A)_{\mathrm{tk}}$ of the tank, the heat gain experiment is conducted first. Let coolant flow through the tank and set the experimental unit at $0^{\circ} \mathrm{C}$. Then stop the coolant circulation and start data recording. Because the surrounding temperature is higher than that of the tank, the average tank temperature increases with time. After $24 \mathrm{~h}$, the heat gain experiment ends and the recording is finished.

Through the heat gain experiment, the heat transfer between the tank and its surroundings can be predicted. Consider the tank as the control volume shown in Fig. 2(a); $T_{\mathrm{i}}$ denotes the initial temperature of the experimental unit, and $T_{\text {sur }}$ denotes the surrounding temperature. After a period $\Delta t$, the temperatures of capsules and coolant become $T_{\mathrm{w}}$ and $T_{\mathrm{f}}$, respectively. The total energy transferred from the surroundings to tank is

$Q_{\text {sur }}=m_{\mathrm{w}} c_{\mathrm{w}}\left(T_{\mathrm{i}}-T_{\mathrm{w}}\right)+m_{\mathrm{f}} c_{\mathrm{f}}\left(T_{\mathrm{i}}-T_{\mathrm{f}}\right)$.

Table 1

Experimental conditions

\begin{tabular}{llll}
\hline No. & $\begin{array}{l}\text { Coolant } \\
\text { flow rate } \\
(1 / \mathrm{min})\end{array}$ & $\begin{array}{l}\text { Inlet coolant } \\
\text { temperature } \\
\left({ }^{\circ} \mathrm{C}\right)\end{array}$ & $\begin{array}{l}\text { Initial capsule } \\
\text { temperature } \\
\left({ }^{\circ} \mathrm{C}\right)\end{array}$ \\
\hline 1 & 5 & -1 & 10 \\
2 & 5 & -3 & 10 \\
3 & 5 & -5 & 10 \\
4 & 10 & -1 & 10 \\
5 & 10 & -3 & 10 \\
6 & 10 & -5 & 10 \\
7 & 20 & -1 & 10 \\
8 & 20 & -3 & 10 \\
9 & 20 & -5 & 10 \\
\hline
\end{tabular}

Table 2

Thermophysical properties of water, ice and coolant

\begin{tabular}{lccc}
\hline Properties & Water & Ice & Coolant \\
\hline Density $\left(\mathrm{kg} / \mathrm{m}^{3}\right)$ & 1000 & 917 & 1045 \\
Specific heat $\left(\mathrm{kJ} / \mathrm{kg}^{\circ} \mathrm{C}\right)$ & 4.18 & 2.01 & 3.65 \\
Thermal conductivity & 0.566 & 2.22 & 0.485 \\
$(\mathrm{~W} / \mathrm{mK})$ & & & \\
Latent heat $(\mathrm{kJ} / \mathrm{kg})$ & 333.6 & - & \multicolumn{1}{l}{-} \\
\hline
\end{tabular}

Table 3

Summary of estimated uncertainties

\begin{tabular}{ll}
\hline Parameter & Uncertainty $(\%)$ \\
\hline Temperature & 1.92 \\
Length & 0.068 \\
Time & 0.42 \\
Flow rate & 1.54 \\
Pressure & 1.68 \\
\hline
\end{tabular}

The rate of heat transfer is written as

$\dot{q}_{\text {sur }}=\frac{Q_{\text {sur }}}{\Delta t}$.

The average overall heat transfer coefficient $(U A)_{\mathrm{tk}}$ of the surface of the tank can be defined as

$\dot{q}_{\text {sur }}=(U A)_{\mathrm{tk}}\left(T_{\text {sur }}-T_{\mathrm{tk}}\right)$,

where

$T_{\mathrm{tk}}=\frac{1}{2}\left(T_{\mathrm{w}}+T_{\mathrm{f}}\right)$.

Fig. 3 indicates the temperature histories of the water inside capsules, the coolant, and the surroundings during the period of $24 \mathrm{~h}$. Utilizing the above-mentioned calculation method, the average $(U A)_{\mathrm{tk}}$ of thermal storage tank is about $1.725 \mathrm{~W} /{ }^{\circ} \mathrm{C}$.

Consider the coolant inside the tank as a control volume shown in Fig. 2(b); the balance energy equation can be written in the form

$\dot{q}_{\mathrm{c}}+\dot{q}_{\text {sur }}=\dot{\mathrm{m}}_{\mathrm{f}}\left(h_{\mathrm{f}, \text { out }}-h_{\mathrm{f}, \text { in }}\right)+m_{\mathrm{f}} \frac{\mathrm{d} h_{\mathrm{fm}}}{\mathrm{d} t}$,

where $\dot{q}_{\mathrm{c}}$ denotes the rate of heat transfer from capsules to the coolant; $\dot{q}_{\text {sur }}$ denotes the rate of heat transfer from the surroundings to the tank across the wall of tank; $m_{\mathrm{f}}$ and $\dot{m}_{\mathrm{f}}$ are the mass and mass flow rate of coolant, respectively; $h_{\mathrm{f}, \text { in }}$ and $h_{\mathrm{f}, \text { out }}$ are the enthalpy of coolant in the inlet and outlet of the tank, respectively; and $h_{\mathrm{fm}}$ denotes the average enthalpy of coolant inside the tank.

From Eq. (4), the rate of cold storage of the tank, $\dot{q}_{\mathrm{s}}$, can be written as

$$
\begin{aligned}
\dot{q}_{\mathrm{s}} & =\dot{q}_{\mathrm{c}}-m_{\mathrm{f}} c_{\mathrm{f}} \frac{\mathrm{d} T_{\mathrm{fm}}}{\mathrm{d} t} \\
& =\dot{m}_{\mathrm{f}} c_{\mathrm{f}}\left(T_{\mathrm{f}, \text { out }}-T_{\mathrm{f}, \mathrm{in}}\right)-(U A)_{\mathrm{tk}}\left(T_{\mathrm{sur}}-T_{\mathrm{fm}}\right),
\end{aligned}
$$

where $T_{\mathrm{f}, \text { in }}, T_{\mathrm{f}, \text { out }}$ and $T_{\mathrm{fm}}$ are the temperatures of inlet and outlet and the average coolant temperature, respectively; $T_{\text {sur }}$ is the temperature of the surroundings; $(U A)_{\mathrm{tk}}$ is the product of overall heat transfer coefficient of tank wall and surface area; and $c_{\mathrm{f}}$ is the specific heat of coolant.

Integrate Eq. (5) with respect to time $t$; the accumulated cold storage of the tank can be obtained as follows:

$$
Q_{\mathrm{s}}(t)=\int_{0}^{t} \dot{m}_{\mathrm{f}} c_{\mathrm{f}}\left(T_{\mathrm{f}, \text { out }}-T_{\mathrm{f}, \text { in }}\right) \mathrm{d} t-(U A)_{\mathrm{tk}} \int_{0}^{t}\left(T_{\text {sur }}-T_{\mathrm{fm}}\right) \mathrm{d} t
$$

or

$Q_{\mathrm{s}}(t)=\sum_{i=1}^{n} \dot{m}_{\mathrm{f}} c_{\mathrm{f}}\left(T_{\mathrm{f}, \text { out }}-T_{\mathrm{f}, \text { in }}\right) \Delta t_{i}-(U A)_{\mathrm{tk}} \sum_{i=1}^{n}\left(T_{\mathrm{sur}}-T_{\mathrm{fm}}\right) \Delta t_{i}$.

The maximum cold storage, $Q_{\max }$, of the tank can be expressed as the sum of the cold storage of capsules and coolant, which is

$Q_{\max }=Q_{\mathrm{PCM}}+Q_{\mathrm{HTF}}$. 

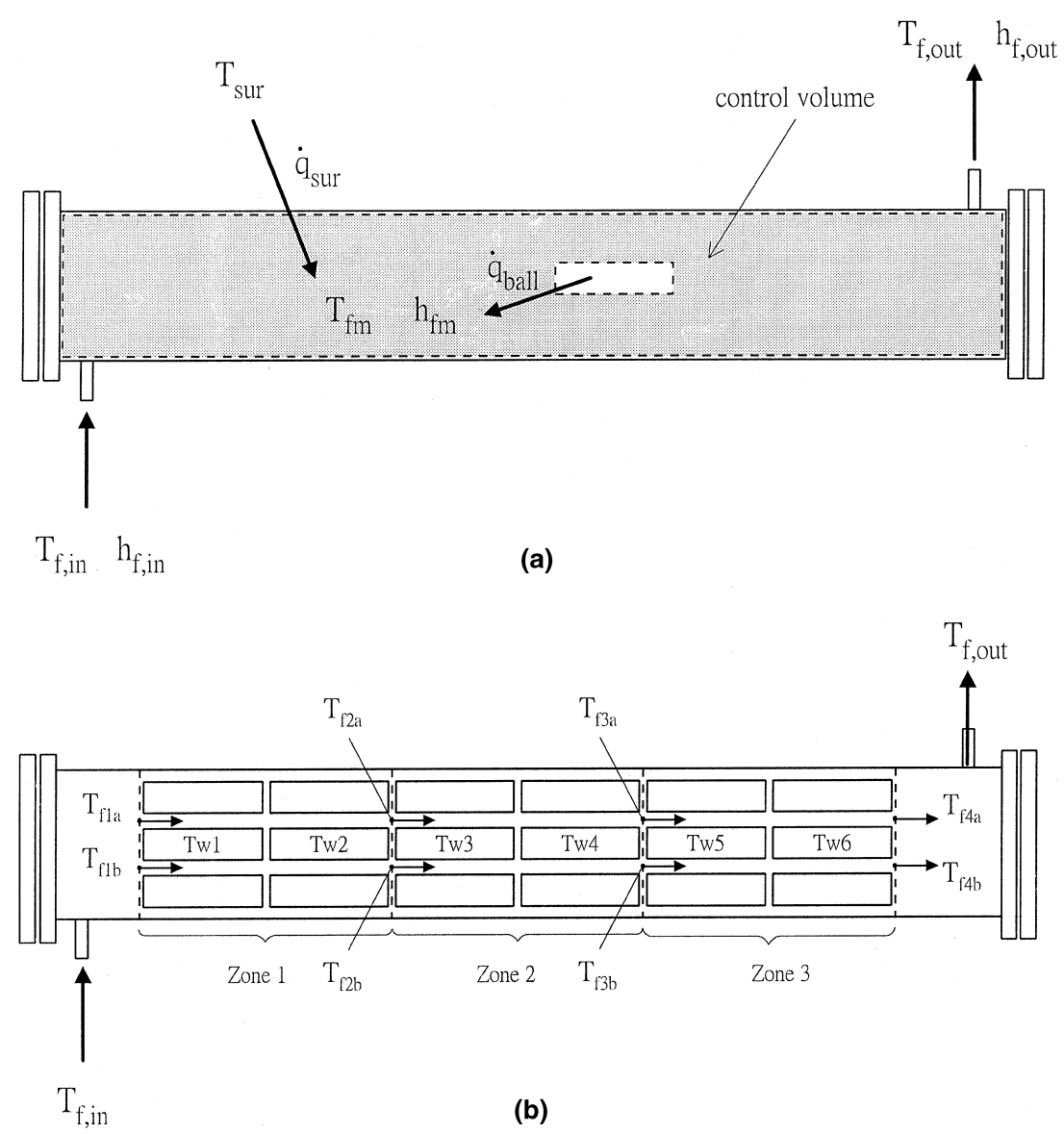

Fig. 2. (a) Diagram of control volume. (b) Symbols of experimental parameters.

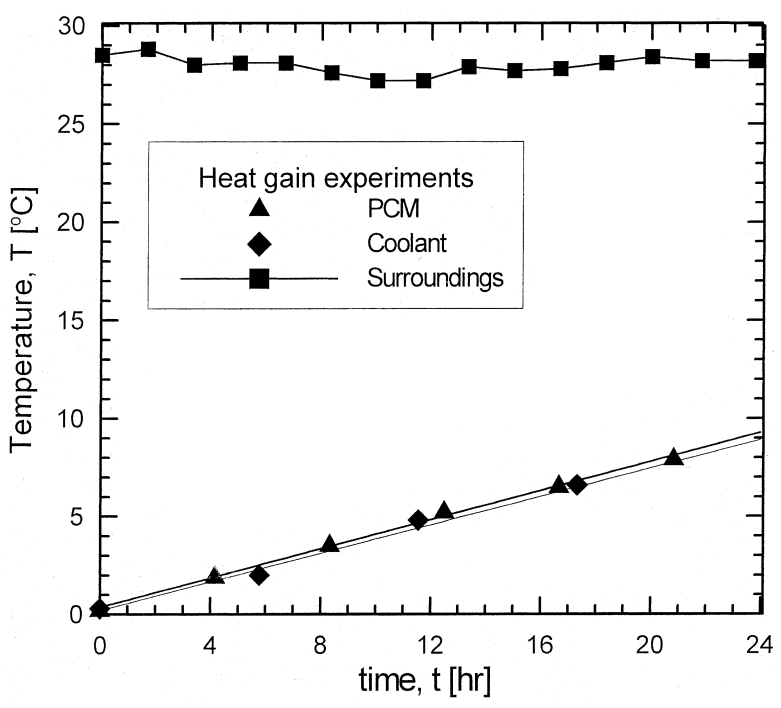

Fig. 3. Heat gain experiments, temperature variation during $24 \mathrm{~h}$.

The cold storage of the capsules is given by

$Q_{\mathrm{PCM}}=m_{\mathrm{w}} c_{\mathrm{w}}\left(T_{\mathrm{i}}-0\right)+m_{\mathrm{w}} \lambda+m_{\mathrm{w}} c_{\text {ice }}\left(0-T_{\mathrm{f}}\right)$.

The cold storage of the coolant is given by
$Q_{\mathrm{HTF}}=m_{\mathrm{f}} c_{\mathrm{f}}\left(T_{\mathrm{i}}-T_{\mathrm{f}}\right)$,

where $T_{\mathrm{i}}$ denotes the initial temperature and $T_{\mathrm{f}}$ denotes the final temperature in a charging process. $m_{\mathrm{w}}$ is the total mass of the water inside capsules, $m_{\mathrm{f}}$ the mass of the coolant; $c_{\mathrm{w}}, c_{\text {ice }}$ and $c_{\mathrm{f}}$ are the specific heat of water, ice and coolant, respectively; and $\lambda$ is the freezing latent heat of water.

\section{Results and discussion}

The typical curve of temperature change of pure water inside a capsule along with the time history during a cooling process is shown in Fig. 4. When a coolant fluid with constant temperature, $T_{\mathrm{f}}$, is used to cool a capsule, the entire cooling process of the water in the capsule can be divided into four stages. The first stage, the process from the initial state with temperature $T_{\mathrm{i}}$ to the subcooling state before water nucleation occurs, is called the sensible heat extraction process. As shown in Figs. 4(a) and (b), water remains in the liquid phase when its temperature drops below the freezing point. The second stage is the process from the occurrence of nucleation to the completion of dendritic ice formation, called the dendritic ice formation process. This process 


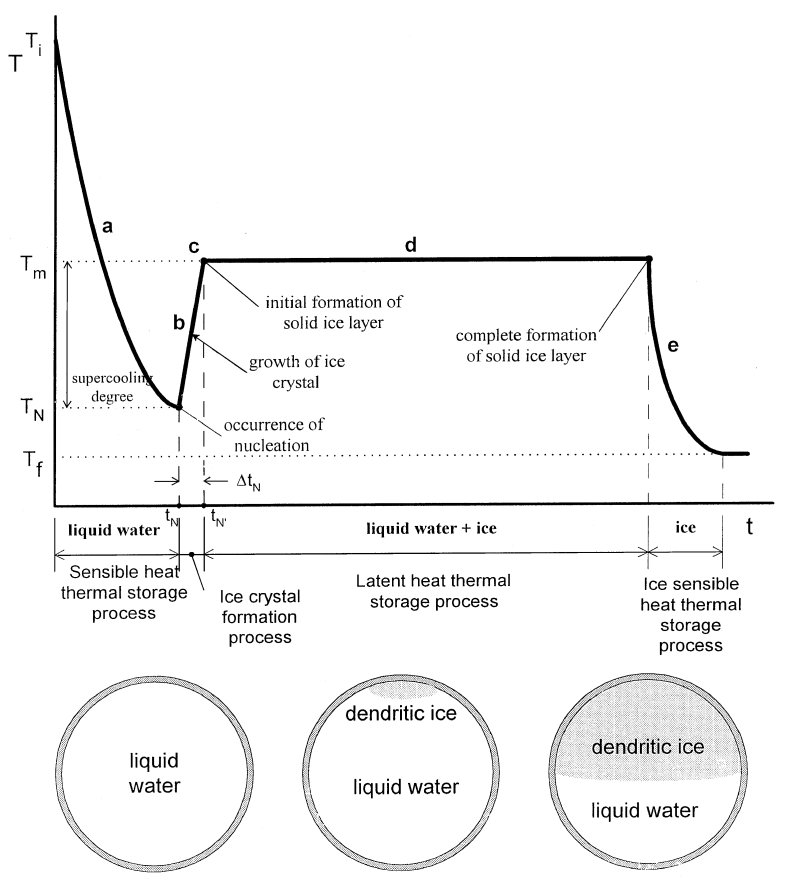

(a)

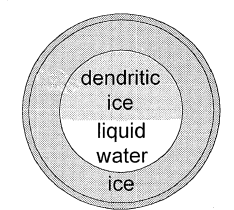

(d)

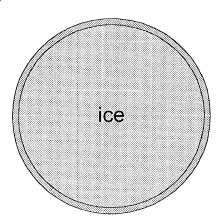

(e) (a)

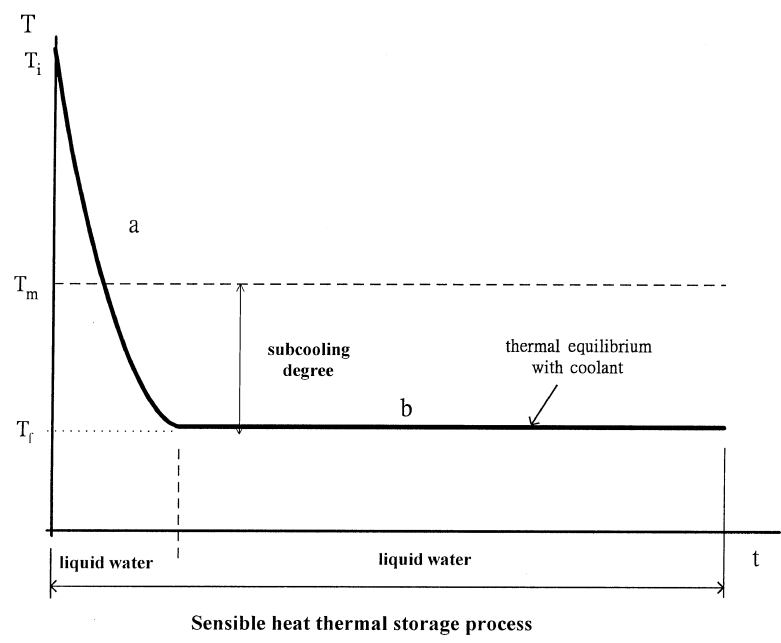

(c)
Fig. 4. (a) Phase change during the cooling process of water inside a ca temperature is $T_{\mathrm{N}}$. Once nucleation occurs, a thin slice of dendritic ice, as shown in Figs. 4(a) and (b), spreads rapidly from the nucleation site down toward the center region of the cylinder, meanwhile it also grows along the cold boundary layer region adjacent to the inner cylinder surface. Latent heat released by dendritic ice enables the supercooled water temperature to rise to the temperature, $T_{\mathrm{m}}$, where ice and water can coexist inside the capsule. Once this equilibrium temperature is reached, the formation of dendritic ice ends. The time experienced by this process is very short, lasting only $1-3 \mathrm{~s}$, depending on the degrees of subcooling. The occurrence of nucleation of water can be easily detected by thermocouple readings, no matter how randomly the nucleation site is located. The third stage involves the phase change process from the completion of ice crystal formation till the complete solidification of water, called the latent heat thermal storage process. As indicated in Figs. 4(a) and (b), a thick ice layer starts to form from the inner surface of capsule toward the capsule center till the water is completely frozen. The last stage involves the process from the cooling of ice till the state where the ice temperature is the same as that of the coolant.This process is similar to the water sensible heat thermal storage process.
Obviously, if the cold energy is stored in the form of latent heat, the water inside the capsule must be released from subcooling. But if it stays in the state of subcooling, cool energy can only be stored in the form of sensible heat, as shown in Fig. 4(b), which decreases the efficiency of the thermal performance of the thermal storage system. While a number of capsules are set in the thermal storage tank for charging, there are many factors which affect the thermal performance of the thermal storage tank. Accordingly, the objective of this paper is to carry out experimental observation and measurement related to the thermal performance of an encapsulated thermal storage tank by varying the inlet coolant temperature and coolant flow rate.

\subsection{Effect of inlet coolant temperature on cold storage}

Figs. 5-7 show the temperature histories of capsules and coolant in different positions along the axial direction of the tank under conditions of the coolant flow rate of $5 \mathrm{1} / \mathrm{min}$ and inlet coolant temperature ranging from $-1^{\circ} \mathrm{C}$ to $-5^{\circ} \mathrm{C}$. For $-1^{\circ} \mathrm{C}$, the water remains subcooled so that the cold energy can only be stored in the form of sensible heat. This indicates that the operating condition of $-1^{\circ} \mathrm{C}$ and $5 \mathrm{1} / \mathrm{min}$ will not make the occurrence of water nucleation possible even though the 


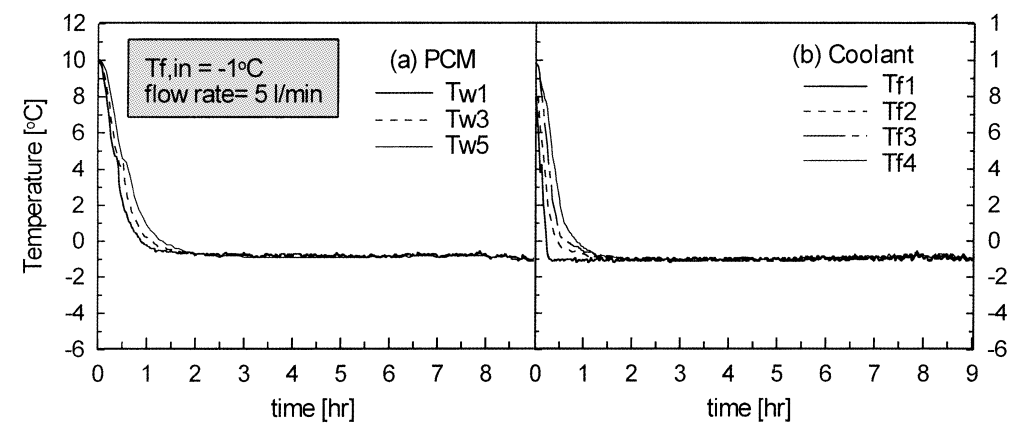

Fig. 5. Temperature variation along axial direction of the tank $\left(Q=51 / \mathrm{min}, T_{\mathrm{f}, \mathrm{in}}=-1^{\circ} \mathrm{C}\right)$ : (a) capsules; (b) coolant.

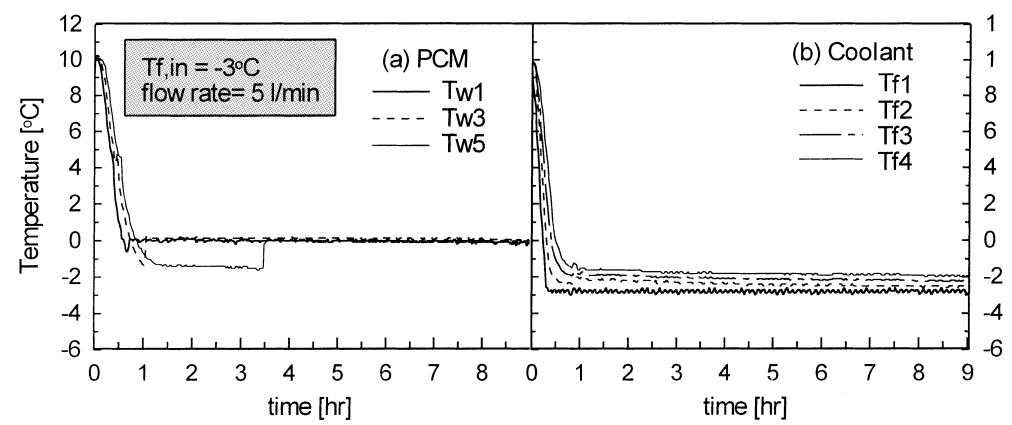

Fig. 6. Temperature variation along axial direction of the tank $\left(Q=5 \mathrm{l} / \mathrm{min}, T_{\mathrm{f}, \mathrm{in}}=-3^{\circ} \mathrm{C}\right)$ : (a) capsules; (b) coolant.

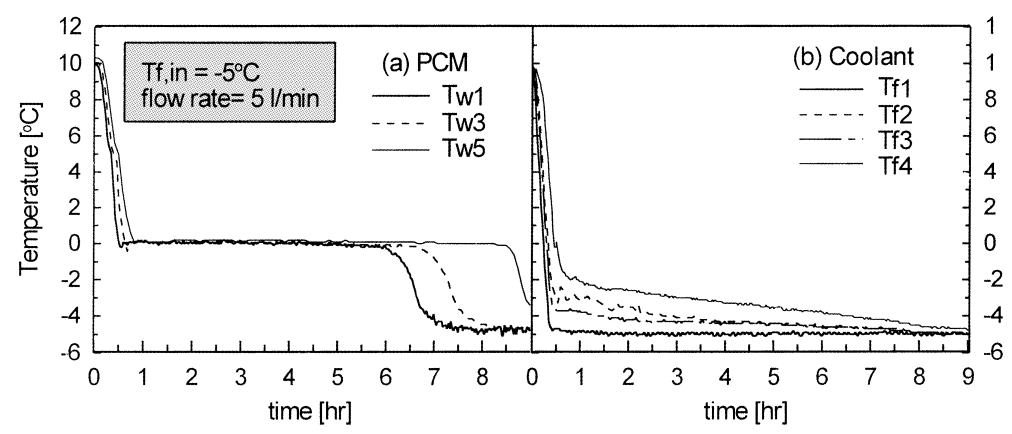

Fig. 7. Temperature variation along axial direction of the tank $\left(Q=51 / \mathrm{min}, T_{\mathrm{f}, \mathrm{in}}=-5^{\circ} \mathrm{C}\right)$ : (a) capsules; (b) coolant.

water is below its freezing point. In the case of $-3^{\circ} \mathrm{C}$, as shown in Fig. 6(a), the nucleation of water inside those capsules arranged in the latter part of tank does not occur until after being subcooled for a long period of time, which therefore fails to finish complete solidification within $9 \mathrm{~h}$. On the other hand, in $-5^{\circ} \mathrm{C}$, the subcooling of water almost does not appear and the entire charging process is finished within $9 \mathrm{~h}$. It is obvious that the inlet coolant temperature seriously affects the onset of the phase change of water, the subcooling time of water and the total charging time. The lower inlet coolant temperature can reduce the subcooling of water and the total charging time. In practical situations a low coolant temperature to promote nucleation is often required in order to establish reasonable heat exchange rates during periods of charging and discharging. Also the coolant temperature for encapsulated ice systems needs to drop progressively during charging since the formation of ice inside the encapsulant acts as a thermal insulator which diminishes the energy extraction rate ability of the storage system.

\subsection{Effect of coolant flow rate on cold storage}

The temperature histories of water are obtained as the coolant flow rate varies from 10 to $201 / \mathrm{min}$ and the inlet coolant temperature varies from $-1^{\circ} \mathrm{C}$ to $-5^{\circ} \mathrm{C}$, as shown in Figs. 8-10. From the above-mentioned discussion, the nucleation of water does not occur on the condition of $-1{ }^{\circ} \mathrm{C}, 5 \mathrm{l} / \mathrm{min}$. Although the coolant flow rate increases from 5 to 10 or $20 \mathrm{l} / \mathrm{min}$, the water inside all capsules still cannot be solidified, as shown in Fig. 8. 


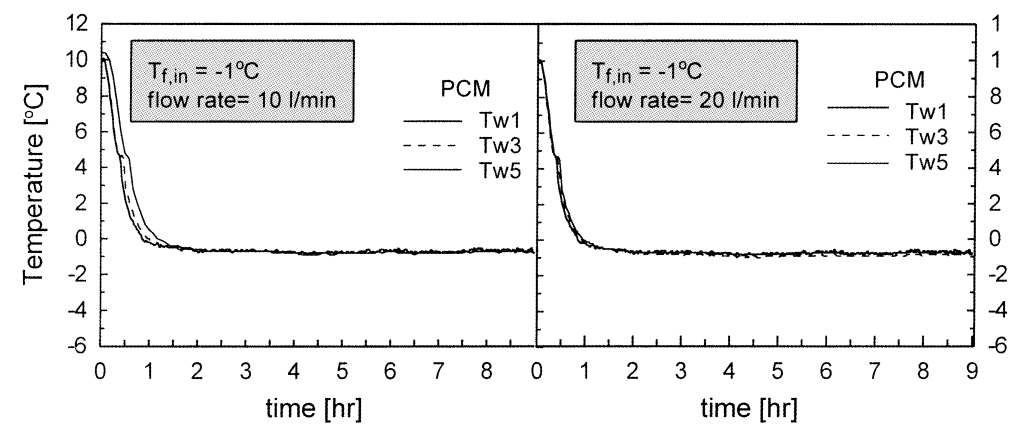

Fig. 8. Temperature variation along axial direction of the tank $\left(T_{\mathrm{f}, \mathrm{in}}=-1^{\circ} \mathrm{C}\right)$ : (a) $Q=10 \mathrm{l} / \mathrm{min}$; (b) $Q=201 / \mathrm{min}$.

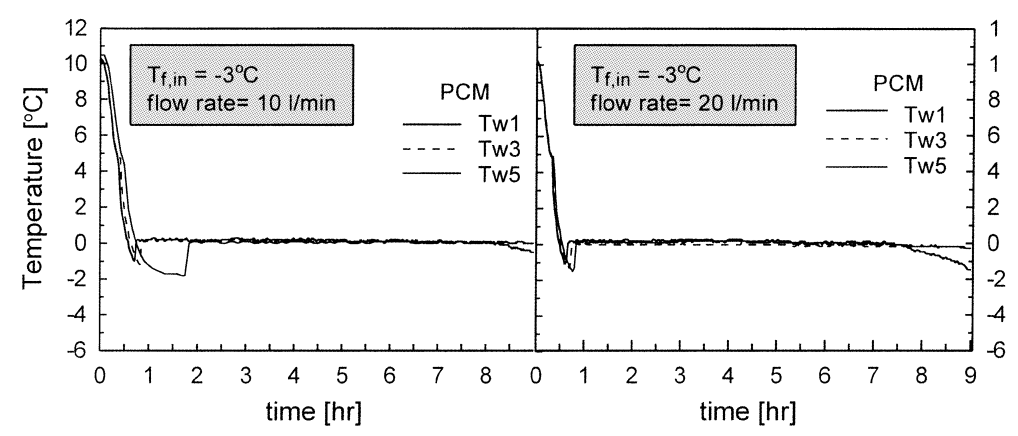

Fig. 9. Temperature variation along axial direction of the $\operatorname{tank}\left(T_{\mathrm{f}, \mathrm{in}}=-3^{\circ} \mathrm{C}\right)$ : (a) $Q=10 \mathrm{l} / \mathrm{min}$; (b) $Q=201 / \mathrm{min}$.

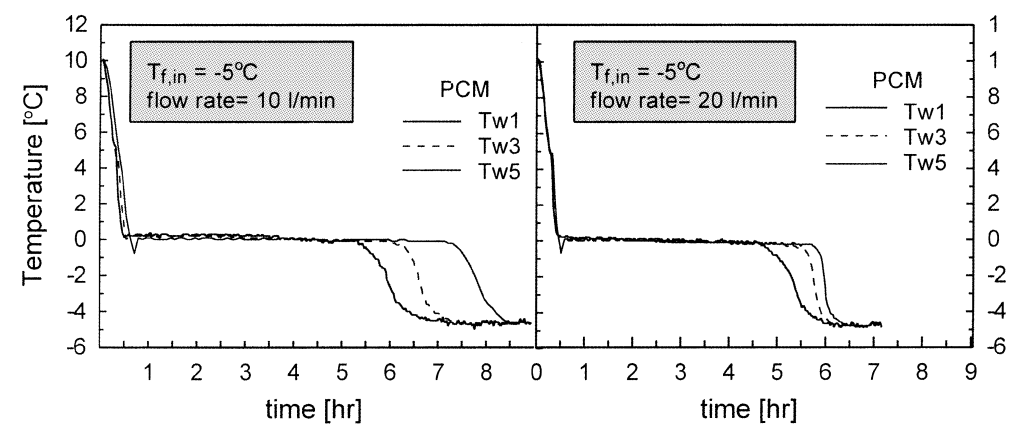

Fig. 10. Temperature variation along axial direction of the tank $\left(T_{\mathrm{f}, \mathrm{n}}=-5^{\circ} \mathrm{C}\right)$ : (a) $Q=10 \mathrm{l} / \mathrm{min}$; (b) $Q=201 / \mathrm{min}$.

That is, if the inlet coolant temperature is not low enough to bring forth water nucleation, the increase of coolant flow rate has no effect on the phase change of water. The result shows that the inlet coolant temperature is a predominate factor in the cold storage of an encapsulated thermal storage tank. As shown in Figs. 810 , given the same inlet coolant temperature, the larger the flow rate, which reduces the degree of subcooling, the shorter the subcooling time and solidification time of water.

In order to discuss the effect of inlet coolant temperature and coolant flow rate on the nucleation of PCM, two specific terms are introduced, namely, fraction of nucleation and fraction of complete frozen. The fraction of nucleation is the ratio of the number of crystallized capsules and the number of total capsules during the charging process. The fraction of complete frozen is the ratio of the number of frozen capsules and the number of total capsules during the charging process. The peak value of both coefficients is 1.0.

According to the experimental results in Chen's [9], the nucleation probability is $100 \%$ with coolant temperature of $-3^{\circ} \mathrm{C}$ or $-5^{\circ} \mathrm{C}$, however, the nucleating time is different. Fig. 11 shows the variation of two coefficients with time under conditions of a coolant inlet temperature of $-3^{\circ} \mathrm{C}$ and different coolant flow rates. The left curves represent the variation of the coefficient of fraction of nucleation, and the right curves represent the variation of the coefficient of fraction of complete frozen. Regardless of time, nucleation takes place in all 

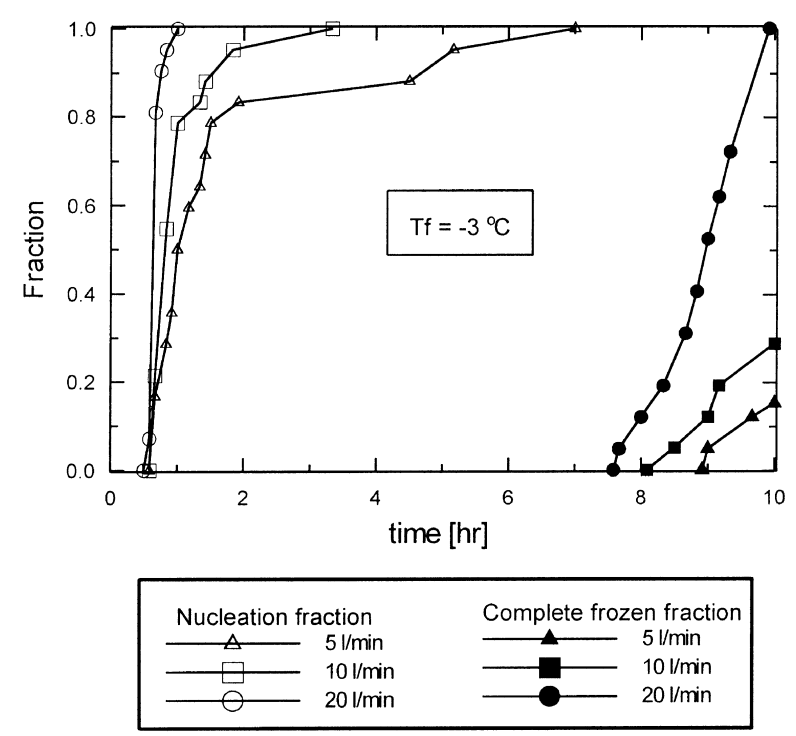

Fig. 11. Fraction of nucleation and fraction of complete frozen for various flow rates $\left(T_{\mathrm{f}, \text { in }}=-3^{\circ} \mathrm{C}\right)$.

capsules in each experiment. However, some capsules nucleate too late to finish the solidification within $9 \mathrm{~h}$. As shown in the right curve, about $80 \%$ of the capsules finish the solidification under coolant flow rate of $20 \mathrm{l} /$ min, and only $10 \%$ achieve the same under $51 / \mathrm{min}$.

The best performance is shown in Fig. 12 under conditions of the coolant inlet temperature of $-5^{\circ} \mathrm{C}$ and different coolant flow rates. The left curves rise sharply to the peak in the first hour, which indicates that all capsules start to nucleate in a short time. Due to the earlier occurrence of nucleation and the stronger cool ability for $-5^{\circ} \mathrm{C}$, every capsule is able to finish charging within $9 \mathrm{~h}$. As shown in the right curves, it takes only $6 \mathrm{~h}$
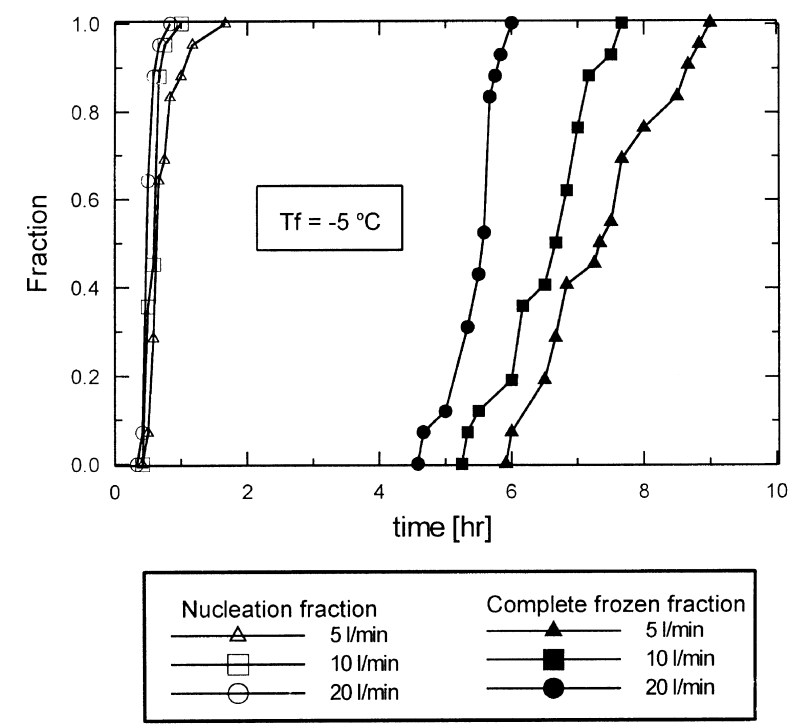

Fig. 12. Fraction of nucleation and fraction of complete frozen for various flow rates $\left(T_{\mathrm{f}, \text { in }}=-5^{\circ} \mathrm{C}\right)$. to finish charging under the fastest condition of $201 / \mathrm{min}$ and about $9 \mathrm{~h}$ under the slowest condition of $5 \mathrm{l} / \mathrm{min}$.

Both parameters provide a criterion for the performance of the thermal storage tank. When the inlet temperature and the flow rate are considered as the performance variables, the match between them becomes an important consideration. Obviously, if the premise of cold storage is to finish charging within $9 \mathrm{~h}$, the condition of $-5^{\circ} \mathrm{C}$ and $51 / \mathrm{min}$ is the lowest threshold to satisfy the requirement.

\subsection{Effect of the temperature and flow rate of coolant on cold storage rate}

If we incorporate the average $(U A)_{\mathrm{tk}}$ of thermal storage tank in Eq. (7), the accumulated cold storage variation with time can be calculated. As indicated in Eq. (8), the maximum cold storage values corresponding to three final coolant temperatures are 3280, 17615, $18030 \mathrm{~kJ}$, respectively, as shown in Fig. 13.

Each cold storage curve is composed of two parts: the front part with a large slope represents the sensible heat cold storage, and the latter part with a small slope represents the latent heat cold storage. Obviously, the latent heat cold storage is the major part of the cold storage. As in the case of $-1{ }^{\circ} \mathrm{C}$ and $51 / \mathrm{min}$, the cool energy is stored only in the form of sensible heat. Therefore, the accumulated cold storage does not increase any more while it attains the maximum amount of sensible heat cold storage. The same results are also shown in the case of 10 and $201 / \mathrm{min}$.

For the condition of $-3^{\circ} \mathrm{C}$ and $51 / \mathrm{min}$, the cold storage curve rises continuously after $9 \mathrm{~h}$ of cold storage, which implies that some capsules remain charging. And the same results are shown in Figs. 13(b) and (c) for 10 and $20 \mathrm{l} / \mathrm{min}$. The most ideal case is $-5^{\circ} \mathrm{C}$ and $20 \mathrm{l} / \mathrm{min}$ shown in Fig. 13(c). It takes about $6.5 \mathrm{~h}$ to reach the maximum amount of cold storage. A conclusion can be drawn from the above discussion: while coolant inlet temperature is higher than the nucleation temperature of water with $0 \%$ nucleation probability, all of the capsules in the thermal storage tank cannot nucleate and only the sensible heat storage is used. If the latent heat storage is to be used, the coolant inlet temperature must be lower than the nucleation temperature of water with $100 \%$ nucleation probability. Given the same coolant inlet temperature, the larger the coolant flow rate, the quicker the cold storage.

\subsection{The overall heat transfer coefficient of the coolant inside the thermal storage tank}

To analyze the convective heat transfer coefficient inside the thermal storage tank, the empirical equation deduced from a lump-system model proposed by Chen [7] is applied, which can be expressed as follows:

$N u_{\mathrm{p}}=\frac{\phi L}{(1-\varepsilon) D_{\mathrm{p}}} \operatorname{Re} e_{\mathrm{p}} P r$ 


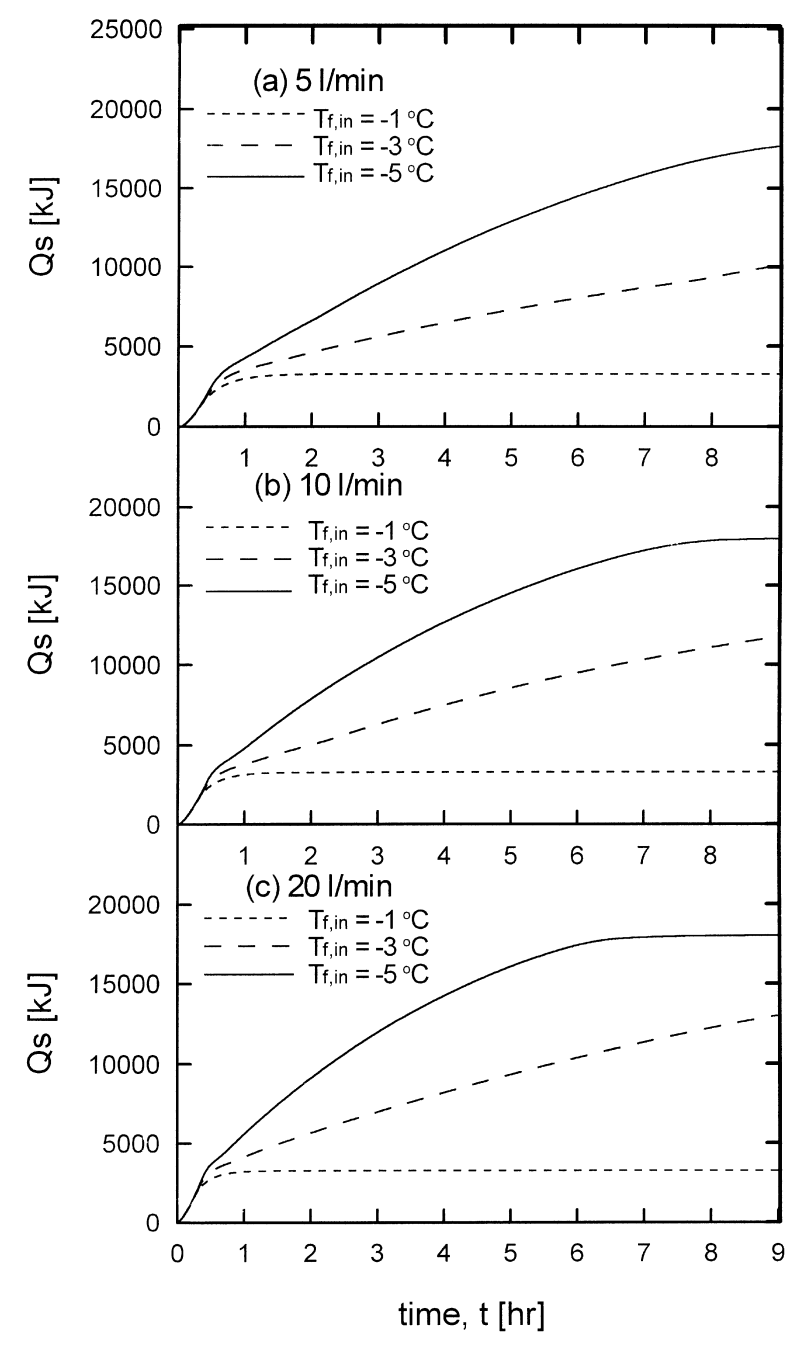

Fig. 13. Accumulation of cold storage.

where $\operatorname{Pr}$ is the Prandtl number; $\phi$ is the shape factor of capsule; $L$ is the length of the thermal storage tank; $\varepsilon$ is the porosity; and $D_{\mathrm{p}}$ is the diameter of the capsule. The $N u_{\mathrm{p}}$ and $R e_{\mathrm{p}}$ are defined as follows:

$N u_{\mathrm{p}}=\frac{h_{\mathrm{f}} D_{\mathrm{p}}}{k_{\mathrm{f}}}$,

$R e_{\mathrm{p}}=\frac{\rho_{\mathrm{f}} u_{0} D_{\mathrm{p}}}{\mu_{\mathrm{f}}}$ where $k_{\mathrm{f}}$ and $\mu_{\mathrm{f}}$ are the thermal conductivity and viscosity of coolant, respectively.

The heat transfer coefficient with different coolant flow rates for $-5^{\circ} \mathrm{C}$ is listed in Table 4. Fig. 14 shows the curves of Nusselt number corresponding to Reynolds number. The black dots and white dots represent the experimental data and Chen's [7], respectively, and the solid line represents the empirical correlation proposed by Chen [7].

The results indicate that Nusselt number increases with Reynolds number. That is, the heat transfer coefficient increases as coolant flow rate increases. The results also agree with Chen's empirical correlation well. Incorporating the experimental data in the empirical correlation, we can obtain the correlation in the following form:

$N u_{\mathrm{p}}=\frac{0.69 L}{(1-\varepsilon) D_{\mathrm{p}}} \operatorname{Re} e_{\mathrm{p}} P r$

\subsection{The effect of coolant flow rate on pressure drop}

The pressure drop can be calculated by using the empirical correlation proposed by Bird [11]. The equation of the pressure drop is

$$
\frac{P_{\text {out }}-P_{\text {in }}}{L}=\frac{C_{A} \mu u_{0}}{D_{\mathrm{p}}^{2}} \frac{(1-\varepsilon)^{2}}{\varepsilon^{3}}+\frac{C_{B} \rho u_{0}^{2}}{D_{\mathrm{p}}} \frac{(1-\varepsilon)}{\varepsilon^{3}},
$$

where $P_{\text {out }}$ and $P_{\text {in }}$ are the outlet and inlet pressures of thermal storage tank, $C_{A}$ and $C_{B}$ the curve-fitting constants, $L$ and $D_{\mathrm{p}}$ the length of thermal storage tank and capsule diameter, $\mu$ and $\rho$ the viscosity and density of the coolant, $u_{0}$ the superficial velocity of the coolant flowing through thermal storage tank without any capsule inside it, and $\varepsilon$ is the porosity.

The pressure drop variation during the charging process is plotted in Fig. 15 for $-5^{\circ} \mathrm{C}$ with different flow rates. The white dots represent the pressure drop before the solidification of the capsules in the period of the sensible heat cold storage when the capsules are yet to dilate. The black dots represent the pressure drop after finishing the charging performance in the period of the latent heat cold storage, and the capsules have dilated.

Due to capsule dilation, the porosity of the thermal storage tank gradually decreases in the charging process. The physical properties listed in Table 2 are used to derive the porosity about 0.378 before solidification of the tank and 0.3264 after solidification. The rate of

Table 4

Heat transfer coefficients

\begin{tabular}{|c|c|c|c|c|}
\hline $\begin{array}{l}\text { Inlet coolant temperature } \\
\left({ }^{\circ} \mathrm{C}\right)\end{array}$ & $\begin{array}{l}\text { Coolant flow rate } \\
(1 / \mathrm{min})\end{array}$ & $\begin{array}{l}\text { Heat transfer coefficient } \\
\left(\mathrm{W} / \mathrm{m}^{2}{ }^{\circ} \mathrm{C}\right)\end{array}$ & $R e_{\mathrm{p}}$ & $N u_{\mathrm{p}}$ \\
\hline-5 & 5 & 41 & 122.1 & 10.5 \\
\hline-5 & 10 & 63 & 243.7 & 62.4 \\
\hline-5 & 15 & 116 & 367.1 & 29.7 \\
\hline-5 & 20 & 143 & 489.6 & 36.6 \\
\hline-5 & 26 & 161 & 634.9 & 41.2 \\
\hline
\end{tabular}




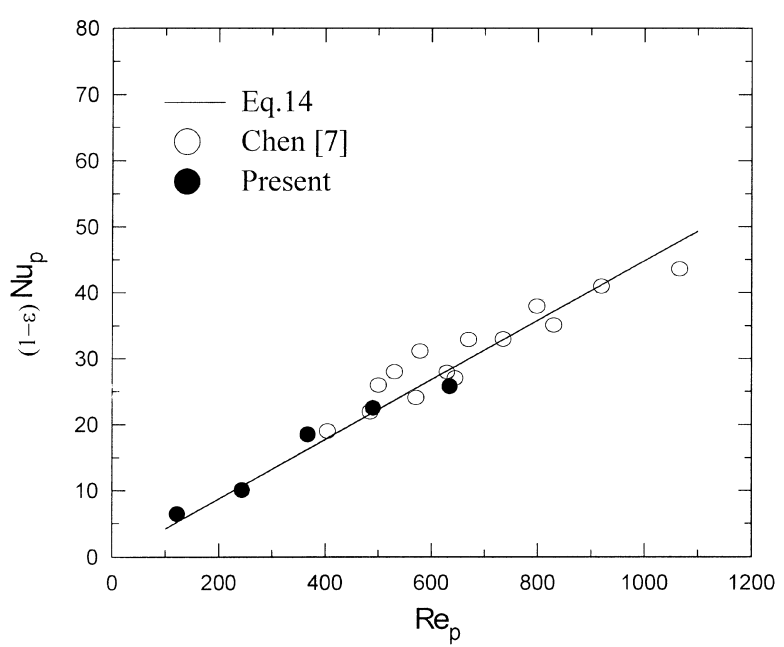

Fig. 14. Heat transfer coefficient.

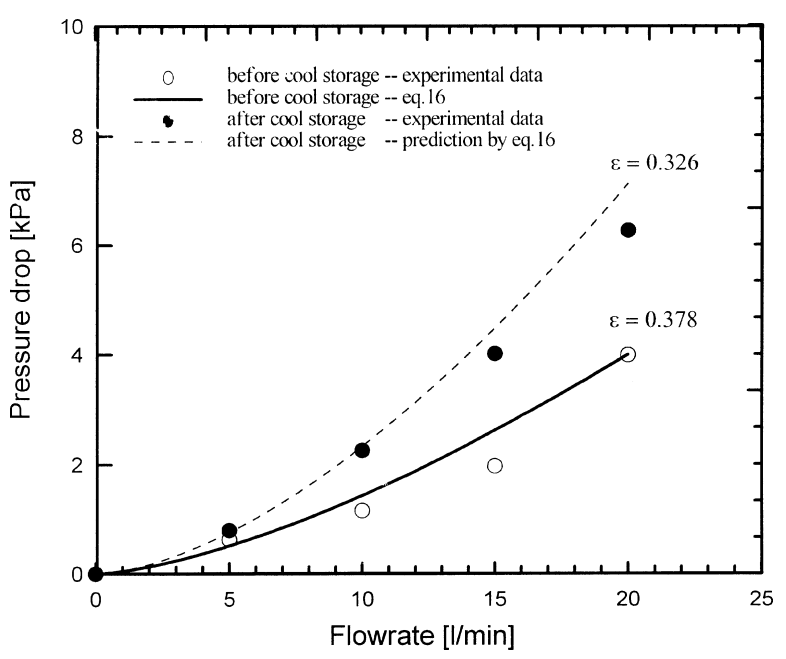

Fig. 15. Variation of pressure drop.

porosity change is about $13.65 \%$. Substituting the experimental data in Eq. (16) to derive the constants, $C_{A}$ and $C_{B}$, the pressure drop can be expressed in the following equation:

$\frac{P_{\text {out }}-P_{\text {in }}}{L}=\frac{99.07 \mu u_{0}}{D_{\mathrm{p}}^{2}} \frac{(1-\varepsilon)^{2}}{\varepsilon^{3}}+\frac{0.625 \rho u_{0}^{2}}{D_{\mathrm{p}}} \frac{(1-\varepsilon)}{\varepsilon^{3}}$.

Obviously, the porosity variation influences the pressure drop. As shown in Fig. 15, the smaller the porosity, the larger the pressure drop, which can also be deduced from Eq. (16). Regardless of the dilation of capsules, the pressure drop increases as the coolant flow rate increases. It indicates that when the coolant flows through packed capsules, the larger the flow rate, the larger the pressure drop. It implies that the pump must provide more flow work to circulate the coolant through the capsules. At the same time, the larger flow rate increases the difference of pressure drop between pre-solidification and post-solidification. That is, the load of the pump varies with time and tends to be enlarged. Since the load of the pump varies during the changing process, the selection of the pump becomes very important.

\section{Conclusions}

This paper investigated the thermal performance of a thermal storage tank during charging process utilizing cylindrical capsules with varying inlet coolant temperature and coolant flow rate. The following conclusions can be drawn from the results:

1. Cool energy can be fully stored in the form of latent heat, if the inlet coolant temperature is lower than the temperature of $100 \%$ probability of crystallization. The lower the inlet coolant temperature, the shorter the time it takes to finish cold storage.

2. When the inlet coolant temperature is set below the temperature of $0 \%$ probability of nucleation, the increase of the coolant flow rate does not have any effect on the crystallization of the PCM. On the contrary, the larger flow rate can reduce the time of crystallization under the condition of inlet coolant temperature with $100 \%$ probability of nucleation.

3. The lower the inlet coolant temperature and the larger the coolant flow rate, the faster the cold storage rate. The heat transfer coefficient increases as the coolant flow rate increases. The pressure drop flowing through tank is enlarged as the coolant flow rate increases during the charging process, and the difference of pressure drop between the pre-solidification and post-solidification also increases as the coolant flow rate increases.

\section{Acknowledgements}

The project is funded by the National Science Council, ROC under project number NSC 86-2221-E002-065.

\section{References}

[1] T. Saitoh, K. Hirose, High-performance phase-change thermal energy storage using spherical capsules, Chem. Eng. Commun. 41 (1986) 39-58.

[2] S. Kondepudi, S. Somasundaram, N.K. Anand, A simplified model for the analysis of a phase-change material-based thermal energy storage system, Heat Recovery Syst. CHP 8 (3) (1988) 247-254.

[3] D.R. Laybourn, Thermal energy storage with encapsulated ice, ASHRAE Trans. 94 (1) (1988) 1971-1988.

[4] D. Arnold, Dynamic simulation of encapsulated ice stores-Part I: the model, ASHRAE Trans. 97 (2) (1990) 1170-1178.

[5] S.L. Chen, An experimental investigation of cold storage in packed capsules with solidification, Int. J. Exp. Heat Transfer 4 (1991) 263-280. 
[6] S.L. Chen, J.S. Yue, A simplified analysis for cold storage in porous capsules with solidification, ASME J. Energy Resour. Technol. 113 (1991) 108-116.

[7] S.L. Chen, J.S. Yue, Thermal performance of cool storage in packed capsules for air conditioning, Heat Recovery Syst. CHP 11 (6) (1991) 551-561.

[8] H.W. Ryu, S.A. Hong, B.C. Shin, S.D. Kim, Heat transfer characteristics of cool-thermal storage systems, Energy 16 (4) (1991) $727-737$.
[9] S.L. Chen, P.P. Wang, T.S. Lee, An experimental investigation of nucleation probability of supercooled water inside cylindrical capsules, Exp. Thermal Fluid Sci. 18 (1999) 299-306.

[10] R.J. Moffat, Using uncertainty analysis in the planning of an experiment, J. Fluids Eng. 107 (1985) 173-182.

[11] R.B. Bird, W.E. Stewart, E.N. Lightfoot, Transport Phenomena, Wiley, New York, 1960, pp. 196-200 (Chapter 6). 